\title{
Identification of restriction endonuclease with potential ability to cleave the HSV-2 genome: inherent potential for biosynthetic versus live recombinant microbicides Misaki Wayengera*1,2,3,4, Henry Kajumbula1,3 and Wilson Byarugaba ${ }^{1,4}$
}

\begin{abstract}
Address: ${ }^{1}$ Restrizymes Biotherapeutics Uganda Limited, Kampala, Uganda, ${ }^{2}$ Restrizymes Corporation- Toronto, Canada, ${ }^{3}$ Division of Molecular Biology, Dept of Microbiology, College of Health Sciences, Makerere University, Upper Mulago Hill Road, P O Box 7072, Kampala, Uganda and ${ }^{4}$ Division of Human and Molecular Genetics, Dept of Pathology College of Health Sciences Makerere University, Upper Mulago Hill Road, P O Box 7072, Kampala, Uganda

Email: Misaki Wayengera* -wmisaki@yahoo.com; Henry Kajumbula - jumbic@hotmail.com; Wilson Byarugaba - wbyarugaba@yahoo.co.uk

* Corresponding author
\end{abstract}

Published: 7 August 2008

Theoretical Biology and Medical Modelling 2008, 5:18 doi:10.1186/1742-4682-5-18

This article is available from: http://www.tbiomed.com/content/5/I//8

(C) 2008 Wayengera et al; licensee BioMed Central Ltd.

This is an Open Access article distributed under the terms of the Creative Commons Attribution License (http://creativecommons.org/licenses/by/2.0), which permits unrestricted use, distribution, and reproduction in any medium, provided the original work is properly cited.

\begin{abstract}
Background: Herpes Simplex virus types I and 2 are enveloped viruses with a linear dsDNA genome of 120-200 kb. Genital infection with HSV-2 has been denoted as a major risk factor for acquisition and transmission of HIV-I. Developing biomedical strategies for HSV-2 prevention is thus a central strategy in reducing global HIV-I prevalence. This paper details the protocol for the isolation of restriction endunucleases (REases) with potent activity against the HSV-2 genome and models two biomedical interventions for preventing HSV-2.
\end{abstract}

Methods and results: Using the whole genome of HSV-2, 289 REases and the bioinformatics software Webcutter2; we searched for potential recognition sites by way of genome wide palindromics. REase application in HSV-2 biomedical therapy was modeled concomitantly. Of the 289 enzymes analyzed; 77(26.6\%) had potential to cleave the HSV-2 genome in $>100$ but $<400$ sites; $69(23.9 \%)$ in > 400 but < 700 sites; and the 9(3.1\%) enzymes: Bmyl, Bsp I286I, Bst2UI, BstNI, BstOI, EcoRII, Hgal, Mval, and Sdul cleaved in more than 700 sites. But for the 4: Pacl, Pmel, Smil, Swal that had no sign of activity on HSV-2 genomic DNA, all I30(45\%) other enzymes cleaved < 100 times. In silico palindromics has a PPV of $99.5 \%$ for in situ REase activity (2) Two models detailing how the REase EcoRIl may be applied in developing interventions against HSV-2 are presented: a nanoparticle for microbicide development and a "recombinant lactobacillus" expressing cell wall anchored receptor (truncated nectin-I) for HSV-2 plus EcoRII.

Conclusion: Viral genome slicing by way of these bacterially- derived R-M enzymatic peptides may have therapeutic potential in HSV-2 infection; a cofactor for HIV-I acquisition and transmission.

\section{Background}

About 38.6 million people worldwide are now living with the Human Immunodeficiency Virus (HIV), which causes AIDS [1]. Heterosexual contact is the predominant mode of transmission of HIV infections worldwide. Women are at particularly increased risk of acquiring HIV through heterosexual contact. Despite this gender disparity, there are to date only limited options by which women may actively protect themselves against HIV. [2]. Recent studies have defined factors that are associated with increased 
susceptibility to HIV-1 [3,4]. Among these, genital infection with herpes simplex virus type 2 (HSV-2) is considered a major cofactor for both sexual transmission and acquisition of HIV-1 [5]. HSV-2 is a member of the genus of double-stranded DNA viruses called simplexvirus. HSV-2 together with its generic relative HSV-1 causes blistering lesions of the cervico-vaginal and oral mucosa, respectively. Fleming and Wasserheit recently provided biological, epidemiological and interventional evidence to support the view that infection with HSV-2 may significantly promote HIV transmission and acquisition [6]. Biologically, they show that HSV-2 does this by disrupting mucosal integrity [6], increasing the genital viral loads and numbers of activated immune cells that are susceptible to HIV-1 tropism $[7,8]$. Specifically, it increases the infectiousness of HIV-infected subjects through increased genital HIV load during a genital HSV-2 recurrence $[7,8]$ by the transactivation of HIV-1 LTR through interaction with HSV proteins (ICPO, ICP4) or the production of proinflammatory chemokines known to enhance HIV-1 replication $[9,10]$. Similarly, HSV-2 may mediate the recruitment of activated CD4+ cells [11] that markedly upregulate HIV replication in HSV-infected lesions [12]. It has recently been shown that HIV-1 interacts at the cellular level to form HIV-1 hybrid virions that are pseudotyped with HSV-1 envelope glycoproteins $\mathrm{gD}$ and $\mathrm{gB}$, thus expanding HIV-1 cell tropism to include mucosal epithelial cells $[13,14]$. This has led to the hypothesis that HSV2 may similarly interact with HIV-1 to form such "pseudotypes" with potential to infect other cells, although a recent study failed to provide evidence for such interaction [15].

In the light of the above evidence, developing biomedical strategies for the prevention of sexual transmission of HSV-2 has become recognized as a critical strategy in the control of sexual transmission of HIV-1 [16]. We recently described pre-integration viral genome slicing [PRINT_GSX] as a novel model for devising antiviral genebased therapies using a retrovirus replication model (HIV cDNA) [17]. This approach explores the natural antiviral defense model inherent in bacteria through a nucleic-acid enzymatic system called the restriction modification (RM) system [18]. Bacteria endowed with R-M systems have been shown to be remarkably resistant to tropism by bacteriophages. Four taxonomic classes of R-M systems are recognized to day, with type II being the most widespread [18]. Type II R-M systems comprise two distinct peptides functioning respectively as restriction endonuclease (REase) and cognate methyltransferase (MTase). As a model illustration of function, class I RMS systems, the evolutionary ancestors of R-M systems, are employed here. The class I RMS of Escherichia coli strain K-12 comprises 6 enzymes, of which the respective genes are located on the bacterial chromosome in a region called an immi- gration island: the hsdS gene, hsdR gene, hsdM gene, $\mathrm{mcrB} / \mathrm{C}$ genes and mrr gene. Products of the first two genes play the central antiviral defense function (by recognizing and splicing the exogenous DNA through recognizing 4-12 base pair palindromes; that is nucleotide sequences that read the same in both directions). The site specific subunit hsdS product serves to recognize the specific 4-12 " palindromic" base pair sequence in the genome of the invading phage, while the hsdR restriction subunit product cleaves the DNA if this site is unmethylated. The other 4 gene products serve to protect the host genome as follows: the hsdM gene product is a methyltransferase that transfers a methyl group from S-adenosylmethionine (SAM) to the DNA at the indicated A residues; the morBC system restricts DNA containing methylcytosine residues; while the mrr system restricts DNA with m6methyladenine or m6-methylcytosine $[19,20]$.

The aim of this study is to extend our previous work on viral genome slicing (GSX) to HSV-2 by identifying REases (DNases) with potent ability to cleave the HSV-2 genome. Although the replicative cycles of some eukaryotic viruses such as HSV-2 do not necessary involve viral genome integration into the host nuclear DNA as occurs for retroviruses, we propose that these REases are equally worth exploring for the development of novel HSV-2 microbicides. Two models are proposed for using the REase EcoRII to target HSV-2: first, by cross-linking the enzyme through the formation of C31G (Savvy) and EcoRII PLGAloaded nanoparticles (nano-C31G-EcoRII); second, by expressing EcoRII in Lactobacillus that also expresses a truncated recombinant form of the receptor nectin-1 (xREPLAB-tN1). The former are nanoparticles that may be explored to develop a model combinational microbicide, while the latter is a model "live" microbicide strategy for diverting and disrupting infectious HSV-2 particles.

\section{Results}

A. HSV-2 genome-wide in silico palindromics: REases with HSV-2 genome cleaving potential

Of the 289 enzymes from the REBASE database analyzed; $77(26.6 \%)$ demonstrated potential to cleave the HSVgenome in $>100$ but $<400$ sites (see table 1 for details) and $69(23.9 \%)$ enzymes cleaved in $>400$ but $<700$ sites (see table 2). Nine (3.1\%) enzymes had more than 700 potential cleavage sites: BmyI, Bsp1286I, Bst2UI, BstNI, BstOI, EcoRII, HgaI, MvaI, and SduI, all of which are Type II restriction enzyme subtype $P$, derived respectively from the bacteria Bacillus mycoides [21], Bacillus sphaericus [22], Bacillus stearothermophilus $2 \mathrm{U}$, Bacillus stearothermophilus [23], Bacillus stearothermophilus O22, Escherichia coli R245 [24], Haemophilus gallinarum [25]Micrococcus varians RFL19 [26] and Streptococcus durans RFL3 [27] (see table $3)$. However, for the 4 that had no sign of activity on HSV2 genomic DNA (PacI, PmeI, SmiI, SwaI - [for details see 
Table I: REase (DNase) enzymes cutting HSV-2 genome in > 100 , but $<400$ sites

\begin{tabular}{|c|c|}
\hline Enzyme name & genomic splices (palindrome) \\
\hline AccBSI & 164(gagcgg) \\
\hline Accl & III (gt/mkac) \\
\hline AcIWI & 225(ggatc) \\
\hline AflIII & 127 (a/crygt) \\
\hline Alw2II & $203(\mathrm{gwgcw} / \mathrm{c})$ \\
\hline Alw26I & 308 (gtctc) \\
\hline Alwl & 225 (ggatc) \\
\hline Apal & 267 (gggcc/c) \\
\hline AspHI & 203 (gwgcw/c) \\
\hline Bbel & $261(\mathrm{ggcgc} / \mathrm{c})$ \\
\hline Bbvl2I & 203 (gwgcw/c) \\
\hline BsaWI & $|3|$ (w/ccggw) \\
\hline Bsell & 155 (actgg) \\
\hline BseNI & 155 (actgg) \\
\hline BsePI & 349 (g/cgcgc) \\
\hline BseRI & 213 (gaggag) \\
\hline BsiHKAl & 203 (gwgcw/c) \\
\hline Bsil & III (ctcgtg) \\
\hline BsmAl & 308 (gtctc) \\
\hline BsmBI & 149 (cgtctc) \\
\hline Bspl20I & 267 (g/ggccc) \\
\hline BspMI & 123 (acctgc) \\
\hline Bpml & 170 (ctggag) \\
\hline BsaAl & 155 (yac/gtr) \\
\hline BsrBI & 164 (gagcgg) \\
\hline Bsrl & 155 (actgg \\
\hline BsrSI & 155 (actgg) \\
\hline BssHII & 349 (g/cgcgc) \\
\hline BssSI & III (ctcgtg) \\
\hline BstZI & 338 (c/ggccg) \\
\hline BssTII & 124 (c/cwwgg) \\
\hline BstDI02I & 164 (gagcgg) \\
\hline BstDEl & 139 (c/tnag) \\
\hline BstF5I & 292 (ggatg) \\
\hline BstX2I & 108 (r/gatcy) \\
\hline BstYI & 108 (r/gatcy) \\
\hline Cfr9l & 286 (c/ccggg) \\
\hline Ddel & 139 (c/tnag) \\
\hline Eagl & 338 (c/ggccg) \\
\hline EclXI & 338 (c/ggccg) \\
\hline Ecol30l & 124(c/cwwgg) \\
\hline EcoT I4I & 124 (c/cwwgg) \\
\hline Ehel & 261 (ggc/gcc) \\
\hline Erhl & 124 (c/cwwgg) \\
\hline Esp3I & 149 (cgtctc) \\
\hline Fokl & 292 (ggatg) \\
\hline Hincll & 105 (gty/rac) \\
\hline Hindll & 105 (gty/rac) \\
\hline Hinfl & 318 (g/antc) \\
\hline $\mathrm{Hphl}$ & 280 (ggtga) \\
\hline Kasl & 261 (g/gcgcc) \\
\hline Maelll & 244 (/gtnac) \\
\hline Mboll & 261 (gaaga) \\
\hline Mfll & 108 (r/gatcy) \\
\hline MroNI & 250 (g/ccggc) \\
\hline Msel & $116(\mathrm{t} / \mathrm{taa})$ \\
\hline Msll & 124(caynn/nnrtg) \\
\hline Nael & 250 (gcc/ggc) \\
\hline
\end{tabular}

Table I: REase (DNase) enzymes cutting HSV-2 genome in > 100 , but $<400$ sites (Continued)

\begin{tabular}{ll}
\hline Narl & 261 (gg/cgcc) \\
NgoAIV & 250 (g/ccggc) \\
NgoMI & 250 (g/ccggc) \\
Nspl & 104 (rcatg/y) \\
Plel & 212 (gagtc) \\
PpuMI & 169 (rg/gwccy) \\
Psp5II & 169 (rg/gwccy) \\
PspAl & 286 (c/ccggg) \\
PspALI & 286 (ccc/ggg) \\
PspOMI & 267 (g/ggccc) \\
SfaNI & 279 (gcatc) \\
Smal & 286 (ccc/ggg) \\
Tfil & 106 (g/awtc) \\
Trull & 116 (t/taa) \\
Tru9l & 116 (t/taa) \\
Tsp45I & 184 (/gtsac) \\
TspRI & 109 (cagtg) \\
Xholl & 108 (r/gatcy) \\
Xmal & 286 (c/ccggg) \\
Xmalll & 338 (c/ggccg)
\end{tabular}

77 total enzymes

additional file 1]), all 130 (45\%) other enzymes cleaved < 100 times. We have previously demonstrated that in silico palindromics, a novel downstream science of genomics for analysis of restriction enzyme activity using Webcutter software version 2, has a PPV of $99.5 \%$ for in situ REase activity [18].

\section{B. Modeling nano-N-9-EcoRII; a nanoparticle that may be explored to develop microbicides against HSV-2}

A model of a nanoparticle that may be explored in microbicide development was conceptualized. We based that conception on the hypothesis that "for viral genome to be rendered susceptible to a REase with potent activity against the HSV-2 genome, the naked HSV-2 genome must be brought into proximity with the REase". For purposes of this modeling, we have theoretically employed chemical two surfactants, Nonoxynol-9 and Savvy (C31G); although several other synthetic detergents with demonstrated safe profiles following repeated application in vaginal mucosa of both humans and animals such as 1.0\% Savvy (C31G) [28]; and plant derivative like Praneem polyherbal suppository and gossypol may serve the purpose. Note that meta-analysis of randomized controlled trials including more than 5000 women for N-9 safety have indicated some evidence of harm through genital lesions; with N-9 not being recommended for HIV and STI prevention[29]; while no serious adverse event was attributable to SAVVY(C31G) use by a Phase 3, double-blind, randomized, placebo-controlled trial [30]. To this regard, for purposes of in-vivo viral envelope-disruption, Savvy and other surfactants with safe profiles in humans may be a better and safer option. The chemical structure and 
Table 2: REase (DNase) enzymesHSV-2 genome cutting in $>\mathbf{4 0 0}$ but less 700 sites

\begin{tabular}{|c|c|}
\hline Enzyme name & genomic splices (palindrome) \\
\hline$A c c B I I$ & 403 (g/gyrcc) \\
\hline Acyl & 671 (gr/cgyc) \\
\hline Afal & $426(\mathrm{gt} / \mathrm{ac})$ \\
\hline Alul & $456(\mathrm{ag} / \mathrm{ct})$ \\
\hline Ama87ı & 613 (c/ycgrg) \\
\hline Aval & 613 (c/ycgrg) \\
\hline Avall & 613 (g/gwcc) \\
\hline Banl & 403 (g/gyrcc) \\
\hline Banll & 520 (grgcy/c) \\
\hline Bbill & 671 (gr/cgyc) \\
\hline Bbvl & 613 (gcagc) \\
\hline Bcol & 613 (c/ycgrg) \\
\hline Bgll & 316 (gccnnnn/nggc) \\
\hline Bmel8I & $613(\mathrm{~g} / \mathrm{gwcc})$ \\
\hline BsaHI & 671 (gr/cgyc) \\
\hline $\mathrm{BsaOI}$ & 634 (cgry/cg) \\
\hline Bsel I8I & 428 (r/ccggy) \\
\hline Bsh I285I & 634 (cgry/cg) \\
\hline BshNI & 403 (g/gyrcc) \\
\hline Bsiel & 634 (cgry/cg) \\
\hline BsmFI & 668 (gggac) \\
\hline BsoBl & 613 (c/ycgrg) \\
\hline Bsp I43I & 449 (/gatc) \\
\hline Bsp143II & $562(\mathrm{rgcgc} / \mathrm{y})$ \\
\hline BsrFI & 428 (r/ccggy) \\
\hline BssAl & 428 (r/ccggy) \\
\hline Bst7II & 613 (gcagc) \\
\hline BstDSI & 699 (c/crygg) \\
\hline BstH2I & $562(\mathrm{rgcgc} / \mathrm{y})$ \\
\hline BstMCl & 634 (cgry/cg) \\
\hline CfrlOl & 428 (r/ccggy) \\
\hline Cfr42l & 400 (ccgc/gg) \\
\hline Cfrl & 698 (y/ggccr) \\
\hline Csp61 & 426 (g/tac) \\
\hline Dpnl & $449(\mathrm{ga} / \mathrm{tc})$ \\
\hline Dpnll & 449 (/gatc) \\
\hline Drall & 450 (rg/gnccy) \\
\hline Dsal & 699 (c/crygg) \\
\hline Eael & 698 (y/ggccr) \\
\hline Eco24I & 520 (grgcy/c) \\
\hline Eco47l & 613 (g/gwcc) \\
\hline Eco52l & 338 (c/ggccg) \\
\hline Eco64l & 403 (g/gyrcc) \\
\hline Ec0881 & 613 (c/ycgrg) \\
\hline EcoOl091 & 450 (rg/gnccy) \\
\hline FriOI & 520 (grgcy/c) \\
\hline Gsul & 170 (ctggag) \\
\hline Haell & $562(\mathrm{rgcgc} / \mathrm{y})$ \\
\hline HgiEl & 613 (g/gwcc) \\
\hline Hin II & 671 (gr/cgyc) \\
\hline Hsp921 & 671 (gr/cgyc) \\
\hline Hsp92II & 434 (catg/) \\
\hline Kspl & 400 (ccgc/gg) \\
\hline Kzo9l & 449 (/gatc) \\
\hline Maell & 581 (a/cgt) \\
\hline Mbol & 449 (/gatc) \\
\hline Msp 171 & 671 (gr/cgyc) \\
\hline MspAll & 633 (cmg/ckg) \\
\hline Ndell & 449 (/gatc) \\
\hline NlallI & 434 (3168 catg/) \\
\hline NspBII & 633 (cmg/ckg) \\
\hline Rsal & 426 (gt/ac) \\
\hline Sacll & 400 (ccgc/gg) \\
\hline Sau3AI & 449 (/gatc) \\
\hline Sfr303I & 400 (ccgc/gg) \\
\hline Sinl & 613 (g/gwcc) \\
\hline Sstll & 400 (ccgc/gg) \\
\hline Taql & $503(\mathrm{t} / \mathrm{cga})$ \\
\hline TthHB8I & $503(\mathrm{t} / \mathrm{cga})$ \\
\hline
\end{tabular}

69 total enzymes
Table 3: REase enzymes cutting HSV-2 genome in 700 or more times

\begin{tabular}{ll}
\hline Enzyme name & genomic splices (palindrome) \\
\hline${ }^{\text {'Bmyl* }}$ & $773(\mathrm{gdgch} / \mathrm{c})$ \\
${ }^{2} \mathrm{Bspl} /\left.286\right|^{*+\#}$ & $773(\mathrm{gdgch} / \mathrm{c})$ \\
$\left.{ }^{3} \mathrm{Bst2U}\right|^{*+}$ & $824(\mathrm{cc} / \mathrm{wgg})$ \\
${ }^{4} \mathrm{BstNI} I^{*+\#}$ & $824(\mathrm{cc} / \mathrm{wgg})$ \\
${ }^{5} \mathrm{BstO} I^{*+}$ & $824(\mathrm{cc} / \mathrm{wgg})$ \\
${ }^{6} \mathrm{EcoR} \mid I^{*+\#}$ & $824(/ \mathrm{ccwgg})$ \\
$\left.{ }^{7} \mathrm{Hgal}\right|^{*+\#}$ & $831(\mathrm{gacgc})$ \\
$\left.{ }^{8} \mathrm{Mval}\right|^{*+\#}$ & $824(\mathrm{cc} / \mathrm{wgg})$ \\
${ }^{9} \mathrm{Sdul}{ }^{*+\#}$ & $773(\mathrm{gdgch} / \mathrm{c})$ \\
\hline
\end{tabular}

*Type II restriction enzyme subtype: $\mathrm{P}$; ${ }^{+}$commercially available; \#Enzyme gene cloned ${ }^{1-9}$ Source of REase: Bacillus mycoides [2I], Bacillus sphaericus [22], Bacillus stearothermophilus 2U, Bacillus stearothermophilus [23], Bacillus stearothermophilus O22, Escherichia coli R245 [24], Haemophilus gallinarum [25] Micrococcus varians RFLI9 [26] and Streptococcus durans RFL3[27]

molecular weight of both N-9 and Savvy are shown in figure 1.

We obtained the chemical formula and molecular weights of the enzyme EcoRII by using its complete gene and protein sequences [[31,32], and [33]]. Protparam software (Expasy, Swissprot) tool was used for this modeling, as described elsewhere [34]. For details of results of the physicochemical parameters of EcoRII, see table 4 and [see additional file 2]. From these results, specifically the values of the anionic and cationic amino acid composition, it may be noticed that EcoRII is overall negatively charged $(-52,+43$; overall molecule charge is -9$)$, providing anions that could bind free $\mathrm{H}^{+}$in the lactic acid of "PLGA". The other measured EcoRII variables included number of atoms, amino acid composition, instability index, aliphatic index, theoretical PI, in vivo half life and grand average hydropathy (GRAVY) and are shown in table 4 . The 3-dimensional structure of EcoRII was modeled from that previously reported [35]; and is available as PDB entry 1 nas 6 in the EMBL protein database (see figure 2).

For the purposes of achieving conjugation and chemical binding between either Savvy or Nonoxynol-9) and EcoRII, we further hypothesized that the aliphatic polyester poly(lactic-co-glycolic acid) (PLGA) may suffice [35]. PLGA is a copolymer that is synthesized by random ringopening co-polymerization of two different monomers, the cyclic dimers (1,4-dioxane-2,5-diones) of glycolic acid and lactic acid on either tin (II) 2-ethylhexanoate, tin(II) alkoxides, or aluminum isopropoxide as catalysts. Owing to its wide solubility, bio-degradability and compatibility, PLGA is used in drug delivery by the formation of nanoparticles [36]. A simplified chemical structure of PLGA is shown in Figure 3. We finally derived a likely chemical structure of a single molecule of the nanoparticles: 1 ) 
A.<smiles>CCc1ccc(OCCO)cc1</smiles>

B.

\section{$\left[\mathrm{C} 14 \mathrm{H} 29 \mathrm{~N}\left(\mathrm{CH}_{3}\right)_{2} \mathrm{O}\right]_{\mathrm{A}^{-}}+\left[\mathrm{C} 16 \mathrm{H} 33 \mathrm{~N}\left(\mathrm{CH}_{3}\right)_{2} \mathrm{CH}_{2} \mathrm{COO}\right]_{\mathrm{B}}^{-}$}

\section{Figure I}

This figure shows the chemical structures of nonoxynol-9 and C3 IG. A. Note the hydrophilic end with the hydroxyl ion at the extreme left; and the hydrophobic hydrocarbon-benzene complex. This property confers on this molecule the ability to complex with both hydrophilic (ionized) and hydrophobic molecules. The chemical formula and molecular mass of a single nonoxynol-9 molecule are respectively $\mathrm{C}_{33} \mathrm{H}_{60} \mathrm{O}_{10}$ and $616.823 \mathrm{~g} / \mathrm{mol}$. B. C3IG is a I:I mixed Micelle of Alkyl dimethyl amine oxide and Alkyl dimethylglycine (betaine).

nano-N-9-EcoRII and Nano-C31G-EcoRII. Both Theses model nanoparticle structures are shown in Figure 4 . We believe that such nanoparticles may be synthesized practically using a two-step emulsion of EcoRII in PLGA followed by addition of $\mathrm{N}-9$ or $\mathrm{C} 31 \mathrm{G}$ rather than polyacrylic acid (PAA) as described elsewhere [35]. Note that it has been assumed that only a single molecule of EcoRII, C31G or N-9 and PLGA will form the nanoparticle, although practically speaking, the relative proportions of the constituent molecules may vary.

\section{Modeling a "recombinant lactobacillus" able to attract and destroy HSV-2}

Additionally, we propose that a recombinant Lactobacillus expressing "truncated nectin-1 and EcoRII" may achieve a "divert and destroy" strategy against HSV-2. That strategy is based on two hypotheses.

First, surface anchoring of the HSV-2 cellular receptor on the cell walls of native vaginal bacteria (and not merely secretory expression) is possible, and may realise a "divert" strategy for HSV-2 genital infection. This hypothesis is based on the following observations and conceptualizations: (i) Lactobacilli exist as a biofilm that acts as a first line of defence over the genital mucosa. This biofilm forms a potential antimicrobial barrier over the epithelia lining. (ii) Enhancing the antiviral properties of Lactobacilli has recently become a strategy for protecting underly- ing susceptible mucosal cells from viral tropism [36-40]. Specifically, we believe that making these cells mimic "susceptible cells" may divert primary HSV-2 infection. Liu et al. [38] have recently engineered Human vaginal Lactobacilli for surface expression of two domain CD 4 using native sequences of a defined length upstream of the unique C-terminal LPQTG cell wall sorting signal and the positively charged C-terminus in a Lactobacillus-based expression system. The modified L. jensenii displayed 2D CD4 molecules that were uniformly distributed on the bacterial surfaces, and recognized by a conformation dependent anti-CD4 antibody, suggesting that the expressed proteins adopted a native conformation. Such Lactobacillus-based surface expression systems, with potential broad applicability, represent a major step toward developing an inexpensive, yet durable approach to topical microbicides for mitigation of heterosexual transmission of HIV and other mucosally transmitted viral pathogens [38]. Heterologous proteins have been expressed on the surfaces of other Gram-positive bacteria via the sortase23-catalyzed cell wall anchoring mechanism [41], including 5 Streptococcus gordonii, Lactobacillus paracasei and Staphylococcus carnosus [41-45]. Assuming that this approach can be used to anchor the HSV-2 surface receptor on their cell walls, these bacteria may "mimic" susceptible underlying cells and become infected with HSV-2. This is what we refer to as the "divert strategy". Although HSV-2 attachment and entry into epithe- 
Table 4: Physiochemical parameters of EcoRII as predicted from the amino acid sequence alignments

\begin{tabular}{|c|c|}
\hline Physicochemical parameter & Value \\
\hline Number of amino acids: & 404 \\
\hline Molecular Weight & 45611 \\
\hline Theoretical PI & 6.10 \\
\hline Total number of negatively charged residues (Asp+Glu) & 52 \\
\hline Total number of positive residues (Arg+Lys) & 43 \\
\hline \multicolumn{2}{|l|}{ Atomic composition: } \\
\hline - Carbon(C) & 2053 \\
\hline - Hydrogen $(\mathrm{H})$ & 3205 \\
\hline - Nitroge(N) & 565 \\
\hline - Oxygen $(O)$ & 393 \\
\hline - Sulfur & 10 \\
\hline Total number of atoms: & 6426 \\
\hline Formula: & $\mathbf{C}_{2053} \mathbf{H}_{3205} \mathbf{N}_{565} \mathbf{O}_{593} \mathbf{S}_{10}$ \\
\hline Extinction coefficients: & 47 I 20(46870) \\
\hline \multicolumn{2}{|l|}{ Estimated half-life(hours) } \\
\hline - (mammalian reticulocytes, in vitro) & 30 hour \\
\hline - (yeast, in vivo) & $>20$ hours \\
\hline - (Escherichia coli, in vivo) & $>10$ hours \\
\hline Instability index: & 45.04 \\
\hline Aliphatic index: & 97.05 \\
\hline Grand average of hydropathicity (GRAVY) & -0.183 \\
\hline
\end{tabular}

lial cells is mediated through a chain of events, a member of the immunoglobulin (Ig) superfamily closely related to the poliovirus receptor (Pvr), PRR1 (also known as HveC, CD111, CLPED1, ED4, HIgR, HVEC, MGC142031, MGC16207, OFC7, PRR, PRR1, PVRR, PVRR1, SK-12, nectin-1), has been found to be the most effective mediator of HSV-2 attachment and viral entry. HveC also mediates the entry of other alphaherpesviruses [46-52]. Krummenacher et al. [52] have cloned and expressed a "truncated" form of HveC (HveCt) in non-permissive insect cell lines (Spodoptera frugiperda or Sf9) using plasmid pCK285 $[46,52]$ to purify soluble proteins. Given that both CD4 and HveCt are members of the immunoglobulin (Ig) superfamily, we predict that cell wall anchored truncated nectin-1 (HveCt) can be expressed in Lactobacillus using a modified form of plasmid pCK285 and the approach recently devised by Liu et al. [38]. Such additional modifications are necessary because the promoter previously used (polyhedrin) to express HveCt in insect cells is specific for baculovirus [46,52]; a construct using a bacterial promoter active in Lactobacillus is needed. For instance, the P23 promoter from Lactococcus lactis created by PCR amplification with the primers 5'-GTGGAGCTCCCCGAAAAGCCCTGACAACCC-3' and 5'GGAAACACGCTAGCACTAACTTCATT-3', as described by Liu et al., may suffice [38].
Second, we have hypothesized that by further modifying these truncated nectin-1(or HveC)-expressing lactobacilli to express restriction enzymes with potent genome slicing potential such as the EcoRII shown here, integration of the HSV-2 genome into them can be halted (through the disruption or destruction of its genome). This further modification would allow for a "divert and destroy" strategy similar to that being explored in HIV [38-40]. It is likely that EcoRII can be expressed in Lactobacilli because a previous genome-wide analysis of the Lac. Plantinuum protein database revealed the presence of Mtase and REase activities derived from Staphylococcus aureus [37]. Plasmidmediated transfer of R-M activity is common in bacteria $[19,20]$, and because EcoRII is originally encoded on a plasmid rather than the E. coli chromosome [24], recombinant transfer of plasmid R245 to Lactobacilli is likely achievable. The additional "destroy" conception is suggested by the approach that bacteria use to resist tropism bacteriophages $[17,18]$. The resultant model recombinant Lactobacillus has been dubbed "xREPLAB-tN1".

\section{Discussion}

This work extends the concept of viral genome slicing (GSX), previously described for human retroviruses as a module for research and development of novel antivirals at the genome level [17], to HSV-2. Because HSV-2 has 


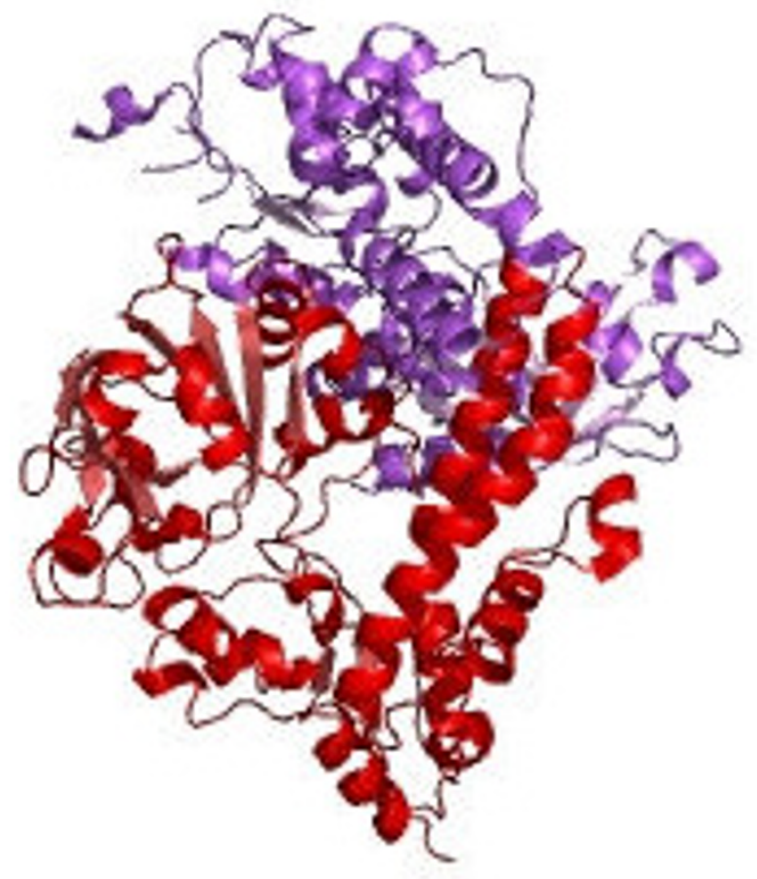

Figure 2

This figure shows the deposited crystal structure of restriction endonuclease EcoRII mutant R88A in the European Molecular Biology Laboratory (EMBL) Protein database (entry I nas6). A detailed structure of the $\mathrm{N}$-domain, which contains the effector-binding cleft of EcoRII with putative DNA-binding residues $\mathrm{H} 36, \mathrm{Y} 4 \mathrm{I}, \mathrm{K} 92$, R94, E96, K97 and R98, can be found from work by Zhou et al. [34].

been noted as a major cofactor in the sexual acquisition and transmission of HIV-1 [5-15], preventing HSV-2 infection in this way may be a potential strategy for reducing the sexual transmission and acquisition of HIV-1.
Here, we detail the first focused effort to identify REases with potential splicing activity against the HSV-2 genome (more than 700 sites) - BmyI, Bsp1286I, Bst2UI, BstNI, BstOI, EcoRII, HgaI, MvaI and SduI - which may be applied to research and the development of HSV-2 biomedical prevention strategies. All 9 of these REase are Type II restriction enzyme subtype $\mathrm{P}$, derived respectively from the bacteria Bacillus mycoides [21], Bacillus sphaericus [22], Bacillus stearothermophilus 2U, Bacillus stearothermophilus [23], Bacillus stearothermophilus O22, Escherichia coli R245 [24], Haemophilus gallinarum [25]Micrococcus varians RFL19 [26] and Streptococcus durans RFL3 [27] (see table 3; details of other cutting enzymes and frequency of splices are shown in tables 1, 2 and [additional file 1]). However, it should be noted that some of these enzymes are isoschizomers that are not significantly active under human physiological conditions. For instance, the three REases derived from Bacillus stearothermophilus have optimal activity at $60^{\circ} \mathrm{C}$ [21-23]. Such characteristics make them impractical for use in the design of microbicides. Therefore, not all these suggested restriction enzymes may actually be successfully applied in both approaches modeled. The enzyme EcoRII was selected because: (1) it is metabolically stable at temperature ranges inclusive of normal human body temperature(see table 4 and additional file 2) [24]; (2) its source, the bacterium Escherichia coli, is similarly a Gram positive bacteria of which the cell wall anchoring system can be modified to express heterologous proteins as in Lactobacillus strains; (3) it exhibits one of the highest slicing potentials against the HSV-2 genome (a strategy that may be beneficial in avoiding spontaneous ligation-see tables 1, 2 and 3); (4) The REase is encoded on plasmids rather than the bacterial chromosome, making its transfer to other bacterial strains possible.

\section{$\left.\mathrm{HO}-\left[\mathrm{CH}\left(\mathrm{CH}_{3}\right) \mathrm{OCO}\right]_{\mathrm{X}}-[\mathrm{CH} 2 \mathrm{OC})\right]_{\mathrm{Y}}-\mathrm{H}$}

\section{Figure 3}

The figure shows a simplified chemical structure of PGLA. X represents lactic acid while y represents glycolic acid. Notice the availability of the hydroxyl $(-\mathrm{OH})$ and free hydrogen $(+\mathrm{H})$ ions at lactic and glycolic extremities of the PLGA molecule respectively. This possibly accounts for diversity of PLGA solvent solubility. PLGA may thus effectively be used to complex both EcoRII and nonoxynol-9 by a two step emulsion of EcoRII first in PLGA; followed by a final emersion in nonoxynol-9. 
A.

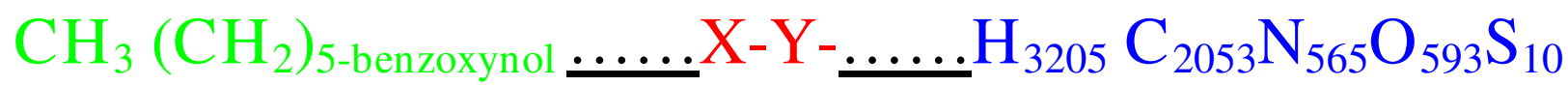

B.

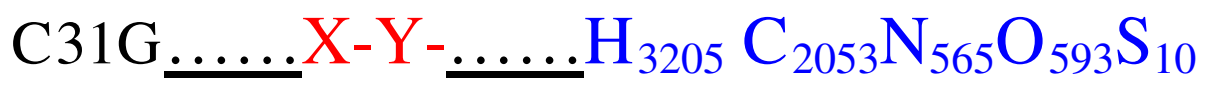

Figure 4

This figure attempts to model the molecular binding of EcoRII to nonoxynol-9 or C3 I G (savvy) through the polyester PLGA. A. N-9 and EcoRII PLGA loaded nanoparticles: Note the orientation of the hydrogen and hydroxyl ions in the glycolic and lactic acids monomers of PLGA towards the hydroxyl and hydrogen ions in the N-9 and the REase nanoparticles model. The underlined dots signify that it is unknown which, covalent or hydrogen, bonds are involved. B. C3IG and EcoRII PLGA loaded nanoparticles. Note that the chemical structure of Savvy is has been abbreviated to C3IG, but is [CI4H29 $\left.\mathrm{N}\left(\mathrm{CH}_{3}\right)_{2} \mathrm{O}\right]_{A^{-}}+\left[\mathrm{Cl} 6 \mathrm{H} 33 \mathrm{~N}\left(\mathrm{CH}_{3}\right)_{2} \mathrm{CH}_{2} \mathrm{COO}\right]_{B}^{-}$.

Several questions remain to be answered about the two proposed models. However, many of them can be addressed fully through in situ experimentation rather than modeling approaches. In both proposed models, it is possible to question whether the additional modifications - (i) cross linking EcoRII to N-9 or C31G (ii) expressing EcoRII in HveCt-expressing Lactobacilli - are relevant. For instance, while it is reasonable to propose that the EcoRII and N-9 or C31G PLGA-loaded nanoparticles may disrupt the viral envelope and possibly the viral capsid, bringing the naked genome into contact with the REase, one could nevertheless argue that the virus is no longer infectious by the time the genome is released from the virion, which would make the REase redundant. A similar argument could be made for the Lactobacillus approach. Once the virus has infected Lactobacillus, it cannot infect the vaginal epithelium, so destruction of the genome by REase appears unnecessary. Moreover, the $\mathrm{N}$ 9 comprised nanoparticles are used here for theoretical purposes, as their use in humans is bound to raise safety concerns emanating from the previous evidence of mucosal irritation and enhancement of both HIV and STI transmission [28]. Never the less, in the absence of experimental evidence based on such nanoparticles, one could still argue their case from the fact that chemotherapeutic agents with noted in-vivo toxicity have been observed to exhibit extensively reduced such adverse effects when complexed into nanoparticles. For instance, DiJoseph et al have recently shown that conjugation of calicheamicin to rituximab with an acid-labile or acid stable linker vastly enhances its growth inhibitory activity against BCL in vitro, has no deleterious effect on the effector functional activity of rituximab, and exhibited greater anti-tumor activity against B cell lymphoma(BCL) xenografts and improved survival of mice with disseminated BCL over that of unconjugated rituximab. Such demonstrated reduced adverse effects of a calicheamicin immunoconjugate of rituximab demonstrate the safety advantage nanoparticles confer to initially unsafe bioactive agents [53].

In the case of the proposed nanoparticle model, it is not fully known by which bonds the REase will combine with the polymer (whether convalent or hydrogen bonds, as shown in figure 4). Such bonds would presumably influence or affect the pattern of release of the components (covalent bonds are stronger and harder to break than hydrogen bonds). Moreover, the chemical models of "N9 or C13G and EcoRII" PLGA-loaded nanoparticles shown in figure 4 propose a single nonoxynol-9 or C31G molecule per REase. However, that may not be the case in the resultant nanoparticles (in situ evaluation of the composition of the nanoparticles is required). In addition, whether the molar concentrations of the respective active ingredients (N-9 or C31G and EcoRII) are sufficient to destabilize the viral envelope and genome, respectively, can only be decided by in situ experiments. Because of its previously demonstrated unsafe profiles in humans [29], any attempts to employ $\mathrm{N}-9$ in such nanoparticles strategies are likely to exploit much lesser concentrations so as to achieve safety. In so doing, that may compromise efficacy for viral envelope disruption. Further still, it is not known whether such polymerization may affect enzyme 
or surfactant activity. Enzyme activities depend on active site conformations, and any changes in the 3D structure will probably influence activity. We have assumed that, since REases are stored in the simple ester construct glycerol, and PLGA is in essence a poly-ester, EcoRII may remain active despite copolymerization. Also, in the proposed nanoparticle model, the involvement of the hydrophilic hydroxyl group of N-9 or C31G or any other detergents in the interaction with PLGA could possibly affect the amphiphatic properties required to disrupt the viral envelope and capsid.

Irrespective of the answers to these questions, such nanoparticles would have advantages of their own. For instance: (i) they help to increase the stability of drugs and possess useful release-control properties; (ii) they offer an increased surface area of action for the drug iii) and enhance efficacy considerably; thereby involve use of lower concentrations of the bioactive agent relative to when used alone[53-55]. Nano-properties i-iii may avail one reason for experimental re-trial of agents like N-9 which has been previously found unsafe for use to prevent HIV or other STI [29]. For such nanoparticles to be applicable in human conditions, it is imperative that we not only determine their size and Zeta potential but safety. In the past, dynamic laser light scattering from the Malvern Zetasizer 3000HAs system (Malvern Instruments, Worcestershire, UK) at $25^{\circ} \mathrm{C}$ at a $90^{\circ}$ angle using PCS 1.61 software has been used to determine both nanoparticle size and Zeta potential $[54,55]$.

The "live microbicide" model also raises unique questions that can only be answered experimentally. First, there is still a need for in situ experiments to evaluate the efficacy of surface anchored HveCt expression by xREPLAB-tN1 in the same way that Liu et al have for 2D CD4[38]. Previous expression of HveCt in insect line lines does not guarantee that it will be successfully expressed in Lactobacillus. Therefore, the efficiency of xREPLAB- $\mathrm{tN} 1$ engineering in respective to HveCt surface expression needs be determined by either (i) Partial purification of HveCt(tN1), (ii) Western analysis of HveCt expression in xREPLAB-N1, (iii) growth phase evaluation of HveCt productivity, or (iv) HSV-2 gD binding assays using whole-cell Lactobacillus extracts and affinity-purified anti-nectin1 antibodies (R7), as has been done elsewhere $[38,52]$. In situ experiments are also required to evaluate potential EcoRII expression, say by Phage $(\lambda)$ DNA digestion assays following REase elution from $L$. jensenni whole cell extracts using electrophoresis, as described elsewhere [56]. Lastly, testing the in vitro safety and efficacy of "xREPLAB-tN1" is mandatory prior to clinical application in humans. We have found no example of a eukaryotic virus infecting a bacterium, so it cannot be guaranteed outright that surface anchoring of HveCt would enable HSV-2 to be diverted into Lactobacilli.
Finally, many genomes of bacteriophages contain unusual nucleic acids bases $[19,20]$. For example, the T-even coliphage DNA contains not cytosine but 5-hydroxymethylcytosine, and most of the hydroxymethylcytosine residues in these DNAs are glycosylated as well [20]. The genome of the B. subtilis phage contains a diversity of thymidine replacements, including uracil, 5-hydroxymethylcytosine, glycosylated or phosphorylated 5 uracil and alpha-glutamyl thymine. These unusual bases serve to render the phage genome resistant to degradation by host restriction enzymes $[19,20]$. It is likely that HSV-2 may become resistant to REase cleavage through similar variations in the viral genomes. This is a likely mechanism for the evolution of resistance to REase-based microbicides. Moreover, R-M systems do not operate with $100 \%$ efficiency, and a small number of phages have been noted to survive and produce progeny in bacteria $[19,20]$. This too may be a shortcoming of REase-based microbicides. We believe that such resistance may be overcome in future by altering the specificity of EcoRII. This concept is based on the fact that among R-M systems of the same class, transfer of the hsdS specificity gene (or protein) occurs naturally and serves to alter the specificity of the "R-M progeny" $[19,20]$. Similar alterations may be achieved through recombinant engineering, which implies application of the other 8 REases with potent cleavage potential against the HSV-2 genome, but with characteristics that make them less than ideal for use in either proposed model. Again, whether the transfer of specificity subunits from REase such as those derived from the Bacillus spp. would entail the persistence of unfavorable characteristics, such as functioning best at temperature ranges outside the normal human physiological range, can only be answered by experiments in situ.

\section{Conclusion}

We identify the REase EcoRII as a potential ingredient of HSV-2 microbicides. Modeled for the first time ever are (i) a nanoparticle for use in research and development of microbicides against HSV-2, and (ii) a "live microbicide" for diverting primary HSV-2 infection from genital mucosal cells coupled to genome disruption. Surfactants with safer profiles may form better candidates for conjugating to EcoRII.

\section{Methods}

\section{A. Identification of REase with potential activity against HSV-2 genome \\ Design}

In silco genome-wide palindromics

\section{Materials and software}

the whole genome of HSV-2 (PAN = NCBI $\mid$ NC 001798 $\mid)$;

289 REases and the bioinformatics software Webcutter2 http://rna.lundberg.gu.se/cutter2/ 
Interventions

we searched for genome splicing sites in a linear pattern in order to recognize 6 or more base-pair palindromes compatible with recognition sites of the 289 REase.

\section{Measured Variables}

cutting enzymes; frequency of splices and specificity palindrome

\section{B. Modeling of the chemical bonding of the nanoparticle nano-N-9-EcoRII}

B1. Chemical structure of nonoxynol-9: Was modeled from that available literature on surfactant groups of microbicides [29]. The Chemical structure of Savvy C31G was also modeled from that available in literature $[28,30]$

\section{B2. Physicochemical properties of EcoRII}

Design

In silco Proteomics

\section{Material and Software}

Protparam Software http://www.expasy.ch/tools/prot param.html; and the EcoRII enzyme accession number = SWISS PROT $|\underline{\text { P14633 }}|$

\section{Interventions}

Direct feeding of amino acid sequences of EcoRII into the protparam interface

\section{Measured variables}

chemical formula of EcoRII and its possible molecular structure Other measured variables included number of atoms, amino acid composition, instability index, aliphatic index, theoretical PI, in-vivo half life and grand average hydropathy (GRAVY).

B3. The likely 3-D structure of EcoRII was obtained from the EMBL protein database using the entry number 1 nas 6 http://www.ebi.ac.uk/pdbsum/1NA6

\section{Modeling of a recombinant lactobacillus for diverting primary mucosal HSV infection}

C1. Primary accession of CD258 antigen; also known as tumor necrosis factor ligand superfamily member 14, which acts as herpesvirus entry mediator-ligand and nectin-1 (also CD111 antigen; herpes virus entry mediator C) were obtained to show that proteins are readily recognized.

C2. A review of the strategies for modifying the plasmid vectors (i) pLEM7, (ii) pOSEL144 pOSEL651, (iii) pVTBac, (iv) PBG38 and (v) pCK285 to generate super plasmids for expression of heterologous proteins in Lactobacillus was done as described elsewhere [38,52].

\section{Competing interests}

All authors are affiliated to Restrizymes Biotherapeutics, a Ugandan biotech pioneering PRINT_GSX for antiviral therapy $R \& D$.

\section{Authors' contributions}

WM conceived of the study, carried out the boinformatics analysis and participated in writing the draft manuscript. WM, BW and KH participated in the modeling, coordinating and writing the final manuscript. All authors read and approved the final manuscript.

\section{Accession Numbers}

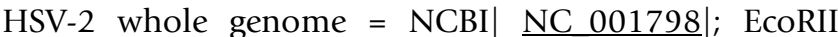
enzyme protein sequence $=$ SWISS PROT $\mid$ P14633 $\mid$; HVEM ligand(aka CD258 antigen) primary accession number $($ PAN $)=$ SWISSPROT $=|\underline{\text { O43557 }}|$; nectin-1 (aka CD111 antigen) PAN = SWISSPROT $\mid$ Q15223 $\mid$, EcoRII mutant R88A 3-D structure PDB entry = EMBL $|\underline{1 \text { nas } 6}|$

\section{Availability \& requirements} http://rna.lundberg.gu.se/cutter2/

http://www.expasy.ch/tools/protparam.html

http://www.ebi.ac.uk/pdbsum/1NA6

\section{Additional material}

\section{Additional File 1}

In-silico palindromic analysis of the 287 study REases in the HSV-2 genome. The data provided represents the various potential cleavage sites in the HSV-2 genome by the 287 REases analyzed.

Click here for file

[http://www.biomedcentral.com/content/supplementary/1742-

4682-5-18-S1.doc]

\section{Additional File 2}

Protparam physicochemical characterization of EcoRII. The data provided represents the protein parameter prediction on the REase EcoRII computed using the protparam software.

Click here for file

[http://www.biomedcentral.com/content/supplementary/17424682-5-18-S2.doc]

\section{Acknowledgements}

The authors received no specific funding for this work. W.M. has in the past, however, received scholarly grant support in this line of study from Virology Educ., the global AIDS vaccine Initiative, Microbicide2008, and the Bill and Melinda Gates AIDS foundation through Keystone.

\section{References}

I. UNAIDS: Report on the global HIV-AIDS epidemic. 2006.

2. Royce RA, Sena A, Cates W Jr, Cohen MS: Sexual transmission of HIV. N Engl J Med 1997, 336: 1072-1078. 
3. Anderson RM: Transmission dynamics of sexually transmitted infections. In Sexually transmitted diseases Volume Chapter 3. 3rd edition. Edited by: Holmes KK, Sparling PF, Mårdh P-A, Lemon SM, Stamm WE, Piot P, et al. New York: McGraw-Hill; 1999:25-37.

4. Hillier $S L$ : The vaginal microbial ecosystem and resistance to HIV. AIDS Res Hum Retrovir 1998, I4(SuppI I):SI7-2I.

5. Wald A, Link K: Risk of human immunodeficiency virus infection in herpes simplex virus type 2-seropositive persons: a meta-analysis. J Infect Dis 2002, I 85(I):45-52.

6. Fleming DT, Wasserheit JN: From epidemiological synergy to public health policy and practice: the contribution of other sexually transmitted diseases to sexual transmission of HIV infection. Sex Transm Infect 1999, 75(1):3-17.

7. del Mar Pujades Rodriguez M, Obasi A, Mosha F, Todd J, Brown D, Changalucha J, Mabey D, Ross D, Grosskurth H, Hayes R: Herpes simplex virus type 2 infection increases HIV incidence: a prospective study in rural Tanzania. Aids 2002, 16(3):451-462.

8. Gray RH, Wawer MJ, Brookmeyer R, Sewankambo NK, Serwadda D, Wabwire-Mangen F, Lutalo T, Li X, vanCott T, Quinn TC: Probability of HIV-I transmission per coital act in monogamous, heterosexual, HIV-I-discordant couples in Rakai, Uganda. Lancet 200I, 357(9263): II49-II 53.

9. Margolis DM, Rabson AB, Straus SE, Ostrove JM: Transactivation of the HIV-I LTR by HSV-I immediate-early genes. Virology 1992, 186(2):788-791.

10. Albrecht MA, DeLuca NA, Byrn RA, Schaffer PA, Hammer SM: The herpes simplex virus immediate-early protein, ICP4, is required to potentiate replication of human immunodeficiency virus in CD4+ lymphocytes. J Virol 1989, 63(5): $186 \mid-1868$.

II. Cunningham AL, Turner RR, Miller AC, Para MF, Merigan TC: Evolution of recurrent herpes simplex lesions. An immunohistologic study. J Clin Invest 1985, 75(1):226-233.

12. Fauci AS: The human immunodeficiency virus: infectivity and mechanisms of pathogenesis. Science 1988, 239(4840):617-622.

13. Zhu ZH, Chen SS, Huang AS: Phenotypic mixing between human immunodeficiency virus and vesicular stomatitis virus or herpes simplex virus. J Acquir Immune Defic Syndr 1990, 3(3):215-219.

14. Calistri A, Parolin C, Pizzato M, Calvi P, Giaretta I, Palu G: Herpes simplex virus chronically infected human $\mathrm{T}$ lymphocytes are susceptible to HIV-I superinfection and support HIV-I pseudotyping. J Acquir Immune Defic Syndr 1999, 2 I (2):90-98.

15. LeGoff J, Bouhlal H, Lecerf M, Klein C, Hocini H, Si-Mohamed A, Muggeridge $M$, Bélec L: LHSV-2- and HIV-I- permissive cell lines coinfected by HSV-2 and HIV-I co-replicate HSV-2 and HIV-I without production of HSV-2/HIV-I pseudotype particles. Virology J 2007, 4:2. doi: I0.1 186/1743-422X-4-2.

16. WHO, UNAIDS: Herpes simplex virus type 2. Programmatic and research priorities in developing countries. $200 \mathrm{I}$.

17. Wayengera M: Pre-Integration gene slicing (PRINT-GSX) as an alternate or complementary gene therapy modem to RNA interference. J Appl Biol Sci 2008, I(2):56-63.

18. Wayengera $M$, Byarugaba $W$, Kajumbula $H$ : Frequency and site mapping of HIV-IISIVcpz, HIV-2/SIVsmm and Other SIV gene sequence cleavage by various bacteria restriction enzymes: Precursors for a novel HIV inhibitory product. Afr J Biotechnol 2007, 6( I0): I 225-I 232.

19. Nelson $M$, McClelland $M$ : Site specific methylation effect on DNA modification methyltransferases and restriction endonucleases. Nucleic Acids Res 1991, 19:2045-2071.

20. Murray N: Type I Restriction systems. Sophisticated molecular machines (a legacy of Bertani and Weigle). Microbial Mol Biol Rev 2002, 64:4I 2-434.

21. Wagner E, Schmitz GG, Kaluza K, Jarsch M, Gotz F, Kessler C: Bmyl, a novel Sdul isoschizomer from Bacillus mycoides recognizing 5'-GDGCH/C-3'. Nucleic Acids Res 1990, I 8:3088.

22. Shibata T, Ikawa S, Kim C, Ando T: Site-specific Deoxyribonucleases in Bacillus subtilis and other Bacillus strains. J Bacteriol 1976, I 28:473-476.

23. Huang L-H, Farnet CM, Ehrlich KC, Ehrlich M: Digestion of highly modified bacteriophage DNA by restriction endonucleases. Nucleic Acids Res 1982, 10:1579-1591.

24. Kosykh VG: Escherichia coli K-12 plasmid R245 controlling EcoRII restriction and DNA modification. Dokl Akad Nauk SSSR 1978, 238: $1227-1230$.
25. Sugisaki $\mathrm{H}$ : Nucleotide sequence of the gene of $\mathbf{H g a l}$ restriction endonuclease. Bull Inst Chem Res Kyoto Univ 1993, 7 I:338-342.

26. Butkus $V$, Klimasauskas $S$, Kersulyte $D$, Vaitkevicius $D$, Lebionka $A$, Janulaitis A: Investigation of restriction-modification enzymes from M. varians RFLI 9 with a new type of specificity toward modification of substrate. Nucleic Acids Res 1985, 13:5727-5746.

27. Janulaitis A, Marcinkeviciene L, Petrusyte M, Mironov A: A new sequence-specific endonuclease from Streptococcus durans. FEBS Lett 1981, 134: I72-174.

28. Patton DL, Sweeney YT, Balkus JE, Hillier SL: Vaginal and rectal topical microbicide development: safety and efficacy of $1.0 \%$ Savvy (C3 IG) in the pigtailed macaque. Sex Transm Dis 2006, 33(I i):69I-695.

29. Wilkinson D, Tholandi M, Ramjee G, Rutherford GW: Nonoxynol9 spermicide for prevention of vaginally acquired HIV and other sexually transmitted infections: systematic review and meta-analysis of randomised controlled trials including more than $\mathbf{5 0 0 0}$ women. Lancet Infect Dis 2002, 2:6I3-7.

30. Feldblum PJ, Adeiga A, Bakare R, Wevill S, Lendvay A, Obadaki F, Olayemi MO, Wang L, Nanda K, Rountree W: SAVVY vaginal gel (C3IG) for prevention of HIV infection: a randomized controlled trial in Nigeria. PLoS ONE 2008, 3(I):el474.

31. Bhagwat AS, Johnson B, Weule K, Roberts RJ: Primary sequence of the EcoRII endonuclease and properties of its fusions with beta-galactosidase. J Biol Chem 1990, 265:767-773.

32. Kossykh VG, Repyk AV, Kaliman AV, Bur'Yanov YI: Nucleotide sequence of the EcoRII restriction endonuclease gene. Biochim Biophys Acta 1989, 1009:290-292.

33. Kossykh VG, Repyk AV, Kaliman AV, Bur'Yanov YI, Baev AA: Primary structure of the gene of restriction endonuclease EcoRII. Dokl Akad Nauk SSSR 1989, 308: I497-I499.

34. Gasteiger E, Hoogland C, Gattiker, Duvaud S, Wilkins MR, Appel RD, Bairoch A: Protein Identification and Analysis Tools on the ExPASy Server. In The Proteomics Protocols Handbook Edited by: Walker JM. Humana Press; 2005:57I-607.

35. Zhou XE, Wang Y, Reuter M, Mücke M, Krüger DH, Meehan EJ, Chen L: Crystal structure of type IIE restriction endonuclease EcoRII reveals an autoinhibition mechanism by a novel effector-binding fold. J Mol Biol 2004, 335(I):307-319.

36. Astete CE, Sabliov CM: Synthesis and characterization of PLGA nanoparticles. J Biomaterials Sci - Polymer Edition 2006, I7(3):247-289.

37. Wayengera $\mathbf{M}$ : A recombinant lactobacillus strain expressing genes coding for restriction enzymes cleaving the HIV genomes for use as a live microbicide strategy against heterosexual transmission of HIV. Afr J Biotechnol 2007, 6(I5): 1750-1756

38. Liu X, Lagenaur LA, Lee PP, Xu Q: Engineering Human Vaginal Lactobacillus for Surface Expression of Two-Domain CD4. Appl Environ Microbiol 2008, 74(15):4626-4635. doi:10.1I28/ AEM.00104-08.

39. Wayengera M: $x R E P L A B: A$ recombinant lactobacillus strain producing restriction enzymes with potent activity against HIV proviral DNA as a Live Microbicide Strategy. In AIDS vaccine Washington, Seattle, Aug 20-23; 2007:P05-0I.

40. Wayengera M: Diverting primary HIV entry and replication to vaginal commensal lactobacillus expressing R-M nucleic enzymatic peptides with potent activity at cleaving proviral DNA as a novel HIV live microbicide strategy. Microbicide New Delhi :Abs-10. 2008 Feb 23-28

41. Navarre WW, Schneewind O: Surface proteins of gram positive bacteria and mechanisms of their targeting to the cell wall envelope. Microbiol Mol Biol Rev 1999, 63:174-229.

42. Beninati C, Oggioni MR, Boccanera M, Spinosa MR, Maggi T, Conti S, Magliani W, De Bernardis F, Teti G, Cassone A, Pozzi G, Polonelli L: Therapy of mucosal candidiasis by expression of an anti-idiotype in human commensal bacteria. Nat Biotechnol 2000, I 8: 1060-1064.

43. Giomarelli B, Provvedi R, Meacci F, Maggi T, Medaglini D, Pozzi G, Mori T, McMahon JB, Gardella R, Boyd MR: The microbicide cyanovirin- $\mathrm{N}$ expressed on the surface of commensal bacterium Streptococcus gordonii captures HIV-I. AIDS 2002, 16:135I-I356.

44. Kruger C, Hu Y, Pan Q, Marcotte H, Hultberg A, Delwar D, Van Dalen PJ, Pouwels PH, Leer RJ, Kelly CG, Van Dollenweerd C, Ma JK, Hammarstrom L: In situ delivery of passive immunity by lacto- 
bacilli producing single-chain antibodies. Nat Biotechnol 2002, 20:702-706.

45. Pant N, Hultberg A, Zhao $Y$, Svensson L, Pan-Hammarstrom Q, Johansen K, Pouwels PH, Ruggeri FM, Hermans P, Frenken L, Boren T, Marcotte H, Hammarstrom L: Lactobacilli expressing variable domain of llama heavy-chain antibody fragments (lactobodies) confer protection against rotavirus-I induced diarrhea. $J$ Infect Dis 2006, 194:1580-1588.

46. Geraghty RJ, Krummenacher C, Eisenberg RJ, Cohen GH, Spear PG: Entry of alphaherpesviruses mediated by poliovirus receptor related protein I and poliovirus receptor. Science 1998, 280:1618-1620.

47. Lopez MF, Eberlé F, Mattei MG, Gabert J, Birg F, Bardin C, Maroc P, Dubreuil P: Complementary DNA characterization and chromosomal localization of a human gene related to the poliovirus receptor-encoding gene. Gene 1995, I55:261-265.

48. Eberlé F, Dubreuil P, Mattei M-G, Devilard E, Lopez M: The human PRR2 gene, related to the poliovirus receptor gene (PVR), is the true homolog of the murine MPH gene. Gene 1995, I 59:267-272.

49. Warner MS, Martinez W, Geraghty RJ, Montgomery RI, Whitbeck JC, Xu R, Eisenberg RJ, Cohen GH, Spear PG: A cell surface protein with herpesvirus entry activity (HveB) confers susceptibility to infection by herpes simplex virus type 2 , mutants of herpes simplex virus type I and pseudorabies virus. Virology 1998 , 246(I): 179-89.

50. Aoki J, Koike S, Asou H, Ise I, Suwa H, Tanaka T, Miyasaka M, Nomoto A: Mouse homolog of poliovirus receptor-related gene 2 product, $\mathbf{m P R R 2}$, mediates homophilic cell aggregation. Exp Cell Res 1997, 235:374-384.

5I. Subramanian RP, Geraghty RJ: Herpes simplex virus type I mediates fusion through a hemifusion intermediate by sequential activity of glycoproteins D, H, L, and B. Proc Natl Acad Sci USA 2007, 104(8):2903-2908.

52. Krummenacher C, Nicola AV, Whitbeck JC, Lou H, Hou W, Lambris JD, Geraghty RJ, Spear PG, Cohen GH, Eisenberg RJ: Herpes simplex virus glycoprotein $\mathrm{D}$ can bind to poliovirus receptorrelated protein I or herpesvirus entry mediator, two structurally unrelated mediators of virus entry. J Virol 1998, 72(9):7064-7074.

53. Dijoseph JF, Dougher MM, Armellino DC, Kalyandrug L, Kunz A, Boghaert ER, et al.: CD20-specific antibody-targeted chemotherapy of non-Hodgkin's B-cell lymphoma using calicheamicin-conjugated rituximab. Cancer Immunology Immunotherapy 2007, 57(7): $1107-1117$.

54. Nam SH, Nam HY, Joo RJ, Baek IS, Park J: Curcumin-Loaded PLGA Nanoparticles Coating onto Metal Stent by EPD. Bull Korean Chem Soc 2007, 28(3):397-402.

55. Betancourt T, Brown B, Brannon-Peppas L: Doxorubicin-lodaed PLGA nanoparticles by nanoprecipitation: preparation, charcterisation and in-vitro evaluation. Nanomedicine 2007, 2(2):219.

56. Lepikhov K, Tchernov A, Zheleznaja L, Matvienko N, Walter J, Trautner TA: Characterization of the type IV restriction modification system Bsp LUI IIII from Bacillus sp. LUII. Nucleic Acids Res 200I, I5:469|-4698.
Publish with Bio Med Central and every scientist can read your work free of charge

"BioMed Central will be the most significant development for disseminating the results of biomedical research in our lifetime. "

Sir Paul Nurse, Cancer Research UK

Your research papers will be:

- available free of charge to the entire biomedical community

- peer reviewed and published immediately upon acceptance

- cited in PubMed and archived on PubMed Central

- yours - you keep the copyright
BioMedcentral 